\title{
Microorganismos Fijadores De Nitrógeno Y Su Acción Complementaria A La Fertilización Química En El Cultivos De Coffea arabica L.
}

\author{
Danilo Santana-Aragone \\ Eduardo Colina-Navarrete \\ Carlos Castro-Arteaga \\ Dalton Cadena-Piedrahita \\ Arianna Sotomayor-Morán
}

Investigadores de la Facultad de Ciencias Agropecuarias

Universidad Técnica de Babahoyo, Ecuador

Edgar Galarza-Centeno

Analista Agropecuario

Ministerio de Agricultura Ganadería, Acuacultura y Pesca, Ecuador

Marlon López-Villacrés

Especialista de Operaciones

Empresa Pública Unidad Nacional de Almacenamiento, Ecuador

doi: 10.19044/esj.2016.v13n3p211 URL:http://dx.doi.org/10.19044/esj.2016.v13n3p211

\begin{abstract}
The objective of this work was to evaluate the effect of nitrogen's fixers complementaries to the chemical fertilization in the coffe groing. Ten treatments were used and three repetitions in plots of twenty-five plants, which were distributed in a complete blocks design at random. For the evaluation of averages were used the Tukey test at 95\% confidence. During the cycle of the crop was evaluated: plant height, stalk diameter per plant, number of branches per plant, number of grains per plant, weight of 100 grains, yield per hectare of gold coffee and an economic analysis of the treatments. As a result of the experiment, it was noticed that the biofertilizers impacted on the development and performance of coffee cultivation, there was also an increase performance with higher values to the witness. The highest performance was submitted with the application of Micro-Asp (Azospirillium brsilense) in a dose of $6 \mathrm{l} / \mathrm{ha}$ in combination with a program of fertilization ( $160 \mathrm{~kg} \mathrm{~N}, 60 \mathrm{~kg}$ P, $75 \mathrm{~kg} \mathrm{K,} 30 \mathrm{~kg} \mathrm{S,} 20 \mathrm{~kg} \mathrm{Mg}, 0.4 \mathrm{~kg} \mathrm{~B}, 0.2$ $\mathrm{kg} \mathrm{Zn)} \mathrm{based} \mathrm{on} \mathrm{the} \mathrm{analysis} \mathrm{of} \mathrm{soil,} \mathrm{achieving} 1118.75 \mathrm{~kg} / \mathrm{ha}$ of gold coffee, the same that is 4.29 times greater than the witness $(260,7 \mathrm{~kg} / \mathrm{ha}$ of gold coffee).
\end{abstract}


Keywords: Biofertilizers, microorganisms, performance

\section{Resumen}

El objetivo de este trabajo fue evaluar el efecto de microorganismos fijadores de nitrógeno complementarios a la fertilización en cultivo de café. Se utilizaron diez tratamientos y tres repeticiones en parcelas de veinticinco plantas, que se distribuyeron en un Diseño de Bloques Completos al Azar. Para la evaluación de medias se utilizó la prueba de Tukey al 95\% de confianza. Durante el ciclo del cultivo se evaluó: Altura de planta, diámetro de tallo por planta, número de ramas por planta, número de granos por planta, peso de 100 granos, rendimiento por hectárea de café oro y un análisis económico de los tratamientos. Como resultado del experimento, se observó que los biofertilizantes incidieron sobre el desarrollo y rendimiento del cultivo de café, se produjo también incremento del rendimiento con valores superiores al testigo. El mayor rendimiento se presentó con la aplicación de Micro-Asp (Azospirillium brasilense) en dosis de 6 l/ha en combinación con un programa de fertilización $(160 \mathrm{~kg} \mathrm{~N}, 60 \mathrm{~kg}$ P, $75 \mathrm{~kg} \mathrm{~K}$, $30 \mathrm{~kg} \mathrm{~S}, 20 \mathrm{~kg} \mathrm{Mg}, 0.4 \mathrm{~kg} \mathrm{~B}, 0.2 \mathrm{~kg} \mathrm{Zn)} \mathrm{basado} \mathrm{en} \mathrm{el} \mathrm{análisis} \mathrm{de} \mathrm{suelo,}$ logrando $1118.75 \mathrm{~kg} / \mathrm{ha}$ de café oro, el mismo que es 4.29 veces mayor al testigo (260.7 kg/ha de café oro).

Palabras clave: Biofertilizantes, micoorganismos, rendimiento

\section{Introducción}

El café es un cultivo importante de la economía ecuatoriana. En el mundo, más de la mitad de la población consume café, si se considera la extensión de la superficie en que se cultiva y la cantidad de gente que depende de su cosecha. A nivel mundial el café ocupa el tercer lugar después del banano y cacao, en importancia económica, el promedio de producción mundial es de 144,7 millones de sacos de 60 kilogramos. En Ecuador, el cultivo de café, se siembra en 23 de las 24 provincias existentes, en aproximadamente 199.215 hectáreas, de las cuales 136.385 hectáreas corresponden a cafetales arábigos y 62.830 hectáreas a café robusta, siendo las provincias de mayor importancia: Los Ríos, Manabí, Loja, El Oro y las provincias amazónicas. El promedio de rendimiento actual es 0,51 toneladas de café oro por hectárea para arábigos y 0,55 toneladas de café oro por hectárea para robusta. Existe un excedente en la producción del grano, esto debido a que la producción abastece el mercado interno y genera un excedente bastante considerable para el mercado externo, siendo Estados Unidos y la Unión Europea los principales mercados (Cofenac, 2013). 
Uno de los problemas fundamentales del cultivo de café en el país es el bajo rendimiento en las fincas productoras. Mucho de esto se debe a que los productores no invierten para mejorar el cultivo, donde en la mayoría de casos solo se dedican a la cosecha. En general, los suelos tropicales presentan deficiencias en contenidos de materia orgánica (MOS) y en consecuencia, se observan deficientes de nitrógeno (Santana, 2014). A pesar de este conocimiento los productores cafetaleros no utilizan ninguna práctica de fertilización o enmiendas para mejorar la nutrición del cultivo.

El empleo de cepas de microorganismos con un alto potencial de acción sobre el crecimiento y desarrollo de las plantas y el estudio de la diversidad biológica será clave para el manejo integral de cultivos (Olalde y Portugal, 1998).

Durante muchos años se ha estudiado en diversos cultivos la aplicación de microorganismos que ayuden en la fijación de nitrógeno atmosférico en el suelo. Estos estudios han demostrado la eficiencia de los mismos no solo en el aspecto mencionado sino en crear condiciones para la planta más favorable para su desarrollo y producción (Santana, 2014).

En los últimos años el estudio de microorganismos asociados a plantas ha sido tema de interés para muchos investigadores, por todos los beneficios que estos pueden aportar a las plantas, entre estas: fijación biológica de nitrógeno, producción de hormonas, así como también la influencia de estos en el ecosistema. Teniendo como referencia el estudio poblacional de Azospirillum en plantas de café, que mostró resultados variados dependiendo del lugar muestreado, en Oaxaca se encontraron las más altas poblaciones de Azospirillum $1.6 \times 10^{7}-1.5 \times 10^{4}$ ufc/g de peso fresco; tanto en campo como en vivero respectivamente, así como también variación en la actividad reductora de acetileno, del total de cepas aisladas todas presentaron fijación de nitrógeno por arriba de $10 \mathrm{nmol} / \mathrm{h} / \mathrm{ml}$ (Jiménez, 2008).

El género Azospirillum pertenece a un grupo de bacterias Gram negativas, habitantes a menudo de la rizósfera de una amplia variedad de plantas, así como en diversas regiones climáticas del mundo; se caracterizan por ser fijadores de nitrógeno, productor de fitohormonas como auxinas, giberelinas y citoquininas, así como produtores de sideróforos y bacteriocinas (Tapia et al., 1990).

Azotobacter es un género de bacterias que puede producir cantidades grandes de limo capsular, siendo un microbio aerobio libre, que vive del suelo y fija el nitrógeno de la atmósfera. Más allá de su uso como un organismo modelo tiene usos biotecnológicos, especialmente para producción de nitrógeno, pues son bacterias Gram-negativas (Clementi, 2006). 
Azotobacter proporciona muchas ventajas. Como reguladores, promueve el crecimiento de las raíces, lo que conllevan a un aumento en la concentración de materia seca, produciendo fitohormonas (Kennedy y Tchan, 1992).

Este tipo de bacterias son consideradas microorganismos de alta biotecnología, teniendo como ventajas: aumentan la capacidad de intercambio catiónico, mejoran la estructura del suelo, aportan bacterias fijadoras de nitrógeno al suelo, también disminuyen las incidencias de plagas y enfermedades en los cultivos, se reduce la aplicación de pesticidas, disminuye la aplicación de abono químico, la aplicación edáfica y foliar en pre y post-siembra, floración y fructificación (Andrade, 2009).

Las bacterias fijadoras de nitrógeno son componentes muy importantes del suelo, para desarrollar la fertilidad del suelo de aumentar el contenido del nitrógeno en las condiciones medioambientales adecuados, las bacterias fijadoras de nitrógeno producen enzimas que toman el nitrógeno en su forma gaseosa de la atmósfera y con los azúcares que obtienen de la planta, fijan el nitrógeno dentro de la biomasa bacteriana, si las bacterias satisfacen sus necesidades de nitrógeno pasan a la planta y pueden absorber niveles elevados de proteína en las plantas (Arias et al., 2008).

En la actualidad, es poca la información generada sobre el uso de los microorganismos captadores de nitrógeno atmosférico, en cultivos de ciclo perenne. Los trabajos de investigación realizados, aún no demuestran qué dosis o qué productos (microorganismos) logran una mayor captación, por lo tanto el desarrollo de la misma debe estar acorde con la aparición de nuevas fórmulas de más fácil manipulación y aplicación, así como su posterior aplicación comercial.

El presente estudio tuvo como objetivo evaluar los efectos de la aplicación de microorganismos fijadores de nitrógeno complementarios a la fertilización química sobre el comportamiento agronómico del cultivo de café a las aplicaciones de varios microorganismos.

\section{Materiales y Métodos}

La presente investigación se realizó entre los meses de febrero diciembre 2013, en los terrenos de la granja experimental de la Facultad de Ciencias Agropecuarias de la Universidad Técnica de Babahoyo, ubicada en el km 7.5 vía a Montalvo. La misma que se estableció en la plantación cafetalera de estos predios; la variedad evaluada es caturra rojo con dos años de desarrollo, con un marco de siembra de tres por tres metros. La zona presenta un clima Tropical húmedo según clasificación de Holdribge, ubicada en las coordenadas geográficas $1^{\circ} 49^{\prime}$ de latitud sur y $79^{\circ} 32^{\prime}$ de longitud oeste, con temperatura promedio anual de $25.5^{\circ} \mathrm{C}$, una precipitación 
media anual de 2.177,8 mm año, humedad relativa de 85 \% y 72 horas de heliofanía promedio mensual.

Los tratamientos que se utilizaron en el ensayo se presentan a continuación:

Tabla 1. Tratamientos.

\begin{tabular}{ccc}
\hline Tratamientos & Dosis/ha & Época de aplicación \\
\hline Azospirillum artesanal & $300 \mathrm{~kg}$ & Trimestral \\
Azospirillum artesanal & $600 \mathrm{~kg}$ & Trimestral \\
Micro-Asp + P.F & $1.0 \mathrm{l}$ & Bimensual \\
Micro-Asp + P.F & $1.5 \mathrm{l}$ & Bimensual \\
Micro-Azot + P.F & $1.0 \mathrm{l}$ & Bimensual \\
Micro-Azot + P.F & $1.5 \mathrm{l}$ & Bimensual \\
Micro-Azot & $1.0 \mathrm{l}$ & Bimensual \\
Micro-Asp & $1.0 \mathrm{l}$ & Bimensual \\
Testigo químico & Según análisis de suelo & Mensual \\
Testigo absoluto & & Sin aplicación \\
\hline
\end{tabular}

- $\quad$ P.F: Programa de fertilización: 160 kg N, 60 kg P, 75 kg K, 30 kg S, $20 \mathrm{~kg} \mathrm{Mg,} 0.4 \mathrm{~kg} \mathrm{B,} 0.2 \mathrm{~kg} Z \mathrm{n}$.

- $\quad$ Testigo químico: 160 kg N, 60 kg P, 75 kg K.

El producto comercial que se utilizó en el ensayo fue Micro-Asp (Azospirillium Brasilense) con una concentración de 1-2 x $10^{9} \mathrm{ufc} / \mathrm{g} . \mathrm{ml} \mathrm{y}$ Micro-Azot (Azotobacter chroococcum) con una concentración de 1-2 x 10 ufc/g.ml, los mismos que son catalogados como biofertilizantes fijadores de nitrógeno.

En los tratamientos con Azospirullum artesanal se realizó aplicaciones trimestrales, al igual que Micro-Asp + Programa de Fertilización (PF) y Micro-Azot + PF se realizó aplicaciones bimensuales; la aplicación fue dirigida sobre el follaje.

Para el desarrollo y evaluación estadística del ensayo se utilizó el diseño experimental Bloque Completo al Azar (BCA), con diez tratamientos y tres repeticiones. Cada unidad experimental consistió en dos hileras de café, con una separación de las mismas de tres metros y cuatro metros de longitud. Para la evaluación y comparación de medias se utilizó la prueba de Tukey al 95\% de confianza. Se evaluó: altura de planta, diámetro de tallo por planta, número de ramas por planta, número de granos por planta, peso de 100 granos, rendimiento por hectárea de café oro y un análisis económico de los tratamientos.

Dentro del manejo del ensayo se realizaron tres podas de formación en los meses de abril, junio y septiembre. El control de malezas se realizó mediante la aplicación de paraquat (1.5 l/ha) dirigido entre las calles; alrededor de las plantas se efectuó una corona con desyerbas manuales. Para controlar las enfermedades foliares típicas del cultivo de café se ejecutó la 
aplicación quincenal de los fungicidas Sulfato de cobre (0.5 l/ha) y Oxido Cúprico (1 kg/ha). El control de insectos se ejecutó con aplicación mensual de Clorpirifos en dosis de 0.5 l/ha; Para satisfacer las necesidades hídricas del cultivo el riego se lo aplico por surcos; en cada campaña de riego se efectuó la fertilización química en el ensayo. El programa de fertilización fue elaborado en base al análisis de suelo (macro y micro elementos) realizado previamente, las aplicaciones se fraccionaron de forma mensual para distribuir uniformemente los nutrientes que las plantas necesitaron.

\section{Resultados}

\section{Altura de planta}

Los resultados de la evaluación realizada a los 30 días y 150 días fueron similares, encontrándose que los tratamientos Azospirillum artesanal 2,400 kg/ha (2.57 m), Micro-Asp 6 l/ha + P.F (2.57 m), Micro-Asp 9 l/ha + P.F (2.6 m), Micro-Azot 6 l/ha + P.F (2.6 m) y Micro-Azot 9 l/ha + P.F (2.56 $\mathrm{m})$, fueron estadísticamente iguales y superiores al resto de tratamientos. Los registros más bajos se presentaron en los tratamientos testigos con $1.29 \mathrm{~m}$ y $1.55 \mathrm{~m}$ respectivamente. Cuando se evaluó a los 240 días, se observó que el tratamiento Micro-Asp 9 l/ha + P.F (3.02 m), fue estadísticamente igual al tratamiento Micro-Azot $6 \mathrm{l} / \mathrm{ha}+$ P.F $(2.73 \mathrm{~m})$ y superior al resto de tratamientos. El registro más bajo se dio en el testigo químico con $1.35 \mathrm{~m}$.

Tabla 2. Valores obtenidos para la variable altura de planta.

\begin{tabular}{ccccc} 
Tratamientos & Dosis/ha & \multicolumn{3}{c}{ Altura de planta } \\
& & 30 d.d.i. & $150 \mathrm{~d}$ d.d.i. & 240 d.d.i. \\
Azospirillum artesanal & $1.200 \mathrm{~kg}$ & $1.76 \mathrm{c}$ & $1.94 \mathrm{c}$ & $2.27 \mathrm{~cd}$ \\
Azospirillum artesanal & $2.400 \mathrm{~kg}$ & $2.57 \mathrm{a}$ & $2.54 \mathrm{a}$ & $2.43 \mathrm{bcd}$ \\
Micro-Asp + P.F & $6.0 \mathrm{l}$ & $2.57 \mathrm{a}$ & $2.42 \mathrm{ab}$ & $2.56 \mathrm{bc}$ \\
Micro-Asp + P.F & $9.0 \mathrm{l}$ & $2.60 \mathrm{a}$ & $2.54 \mathrm{a}$ & $3.02 \mathrm{a}$ \\
Micro-Azot + P.F & $6.0 \mathrm{l}$ & $2.60 \mathrm{a}$ & $2.56 \mathrm{a}$ & $2.73 \mathrm{ab}$ \\
Micro-Azot + P.F & $9.0 \mathrm{l}$ & $2.56 \mathrm{a}$ & $2.63 \mathrm{a}$ & $2.53 \mathrm{bc}$ \\
Micro-Azot & $6.0 \mathrm{l}$ & $2.22 \mathrm{~b}$ & $2.11 \mathrm{c}$ & $2.12 \mathrm{~cd}$ \\
Micro-Asp & $6.0 \mathrm{l}$ & $2.22 \mathrm{~b}$ & $2.23 \mathrm{bc}$ & $2.03 \mathrm{~d}$ \\
Testigo químico & $160 \mathrm{~kg}$ N-60 kg P-75 kg & $2.04 \mathrm{~b}$ & $2.05 \mathrm{c}$ & $1.35 \mathrm{e}$ \\
\multicolumn{2}{c}{$\mathrm{K}$} & $1.29 \mathrm{~d}$ & $1.55 \mathrm{~d}$ & $1.53 \mathrm{e}$ \\
Testigo absoluto & $0-0-0$ & 2.24 & 2.26 & 2.26 \\
\multicolumn{2}{c}{ Coeficiente de variación \% } & 3.91 & 4.81 & 7.06 \\
\hline
\end{tabular}

\section{Diámetro de tallo por planta}

En la evaluación a los 30 días se encontró que los tratamientos Azospirillum artesanal 2,400 kg/ha (62.67 cm), Micro-Asp 6 l/ha + P.F (64 $\mathrm{cm}$ ), Micro-Asp 9 l/ha + P.F (63 cm), y Micro-Azot 9 l/ha + P.F $(64.67 \mathrm{~cm})$, fueron estadísticamente iguales y superiores al resto de tratamientos. El 
registro más bajo se presentó en el testigo absoluto, con un valor de 26.33 cm. Las observaciones a los 150 días reportaron, que los tratamientos Micro-Asp 9 l/ha + P.F (67.33 cm) y Micro-Azot 9 l/ha + P.F $(66.67 \mathrm{~cm})$, fueron estadísticamente iguales y superiores al resto de tratamientos. El registro más bajo se dio con la aplicación de Azospirillum artesanal 1,200 $\mathrm{kg} / \mathrm{ha}$ con $26.33 \mathrm{~cm}$. Con 240 días después del inicio del ensayo, se observó que el tratamiento Micro-Azot 6 l/ha + P.F $(66.33 \mathrm{~cm})$, fue estadísticamente superior al resto de tratamientos. El menor promedio estuvo en el testigo con $27.67 \mathrm{~cm}$.

Tabla 3. Valores obtenidos para la variable diámetro de tallo.

\begin{tabular}{|c|c|c|c|c|}
\hline \multirow{2}{*}{ Tratamientos } & \multirow{2}{*}{ Dosis/ha } & \multicolumn{3}{|c|}{ Diámetro de tallo (cm) } \\
\hline & & 30 d.d.i. & 150 d.d.i. & 240 d.d.i. \\
\hline Azospirillum artesanal & $1,200 \mathrm{~kg}$ & 36.33 cd & $26.33 \mathrm{e}$ & $36.67 \mathrm{~cd}$ \\
\hline Azospirillum artesanal & $2,400 \mathrm{~kg}$ & $62.67 \mathrm{a}$ & 43 cde & 40 bcd \\
\hline Micro-Asp + P.F & 6.01 & $64 \mathrm{a}$ & $65.33 \mathrm{ab}$ & $42.67 \mathrm{bcd}$ \\
\hline Micro-Asp + P.F & 9.01 & 63 a & 67.33 a & $59.33 \mathrm{ab}$ \\
\hline Micro-Azot + P.F & 6.01 & $55 \mathrm{ab}$ & $64 \mathrm{abc}$ & $51 \mathrm{abc}$ \\
\hline Micro-Azot + P.F & 9.01 & 64.67 a & 66.67 a & $60.33 \mathrm{ab}$ \\
\hline Micro-Azot & 6.01 & $52.67 \mathrm{abc}$ & 49 abcd & 66.33 a \\
\hline Micro-Asp & 6.01 & 50.33 abc & $\begin{array}{l}44.33 \\
\text { bcde }\end{array}$ & 48.33 abcd \\
\hline Testigo químico & $\begin{array}{c}160 \mathrm{~kg} \text { N-60 kg P-75 kg } \\
\text { K }\end{array}$ & $40.67 \mathrm{bcd}$ & 39.67 de & $36.33 \mathrm{~cd}$ \\
\hline Testigo absoluto & $0-0-0$ & $26.33 \mathrm{~d}$ & 35.33 de & $27.67 \mathrm{~d}$ \\
\hline \multicolumn{2}{|c|}{ Promedios } & 51.57 & 50.10 & 46.87 \\
\hline \multicolumn{2}{|c|}{ Coeficiente de variación \% } & 11.51 & 15.23 & 15.97 \\
\hline
\end{tabular}

\section{Número de ramas por planta}

Los promedios de número de ramas por planta encontrados, se muestran en la Tabla 4. La prueba de Tukey al 95\% de confianza determinó que el tratamiento Micro-Azot 6 l/ha + P.F (144), fue estadísticamente igual al tratamiento Micro-Azot 9 l/ha + P.F (129) y superior al resto de tratamientos, registrándose el promedio más bajo con la aplicación de Azospirillum artesanal en dosis de 2,400 kg/ha con 44 ramas. 
Tabla 4. Valores obtenidos para número de ramas por planta

Tratamientos

Azospirillum artesanal

Azospirillum artesanal

Micro-Asp + P.F

Micro-Asp + P.F

Micro-Azot + P.F

Micro-Azot + P.F

Micro-Azot

Micro-Asp

Testigo químico

Testigo absoluto
Dosis/ha

$1,200 \mathrm{~kg}$

$2,400 \mathrm{~kg}$

6.01

9.01

6.01

9.01

6.01

6.01

$160 \mathrm{~kg}$ N-60 kg P-75 kg K

0-0-0
Número de ramas por planta

$53 \mathrm{~cd}$

$44 \mathrm{~d}$

$55 \mathrm{~cd}$

$77 \mathrm{~cd}$

144 a

$129 \mathrm{ab}$

$67 \mathrm{~cd}$

84 bcd

$99 \mathrm{abc}$

$54 \mathrm{~cd}$

80.6

21.68

\section{Número de granos por planta}

En la Tabla 5, se observan los promedios de número de granos por planta encontrados. El tratamiento con mayor número de granos por planta fue Azospirillum artesanal en dosis de $2,400 \mathrm{~kg} / \mathrm{ha}$ con 671 granos/planta, presentándose menor cantidad de granos en el testigo con 302 granos/planta.

Tabla 5. Valores obtenidos para número de granos por planta

\begin{tabular}{ccc} 
Tratamientos & Dosis/ha & Numero de granos por planta \\
Azospirillum artesanal & $1,200 \mathrm{~kg}$ & 356 \\
Azospirillum artesanal & $2,400 \mathrm{~kg}$ & 671 \\
Micro-Asp + P.F & $6.0 \mathrm{l}$ & 643 \\
Micro-Asp + P.F & $9.0 \mathrm{l}$ & 556 \\
Micro-Azot + P.F & $6.0 \mathrm{l}$ & 380 \\
Micro-Azot + P.F & $9.0 \mathrm{l}$ & 431 \\
Micro-Azot & $6.0 \mathrm{l}$ & 433 \\
Micro-Asp & $6.0 \mathrm{l}$ & 436 \\
Testigo químico & $160 \mathrm{~kg}$ N-60 kg P-75 kg K & 406 \\
Testigo absoluto & $0-0-0$ & 302 \\
\multicolumn{2}{c}{ Coeficiente de variación \% } \\
\multicolumn{2}{c}{ Promedios } & 461.4 \\
\hline
\end{tabular}

\section{Peso de 100 granos cereza}

La Tabla 6, detalla los promedios de peso de 100 granos de café

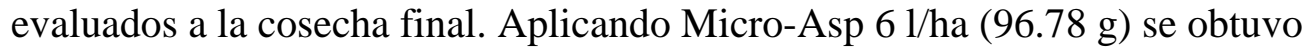
un peso estadísticamente superior a Micro-Asp 6 l/ha + P.F (47.44 g); sin embargo este fue estadísticamente igual a los demás tratamientos. 
Tabla 6. Peso de 100 granos (cereza)

\begin{tabular}{ccc} 
Tratamientos & Dosis/ha & Peso de 100 granos (g) \\
Azospirillum artesanal & $1,200 \mathrm{~kg}$ & $86.67 \mathrm{ab}$ \\
Azospirillum artesanal & $2,400 \mathrm{~kg}$ & $84.67 \mathrm{ab}$ \\
Micro-Asp + P.F & $6.0 \mathrm{l}$ & $47.44 \mathrm{~b}$ \\
Micro-Asp + P.F & $9.0 \mathrm{l}$ & $61.11 \mathrm{ab}$ \\
Micro-Azot + P.F & $6.0 \mathrm{l}$ & $56.55 \mathrm{ab}$ \\
Micro-Azot + P.F & $9.0 \mathrm{l}$ & $55.44 \mathrm{ab}$ \\
Micro-Azot & $6.0 \mathrm{l}$ & $54 \mathrm{ab}$ \\
Micro-Asp & $6.0 \mathrm{l}$ & $96.78 \mathrm{a}$ \\
Testigo químico & $160 \mathrm{~kg}$ N-60 kg P-75 kg K & $56.67 \mathrm{ab}$ \\
Testigo absoluto & $0-0-0$ & $88.89 \mathrm{ab}$ \\
\multicolumn{2}{c}{ Coeficiente de variación \% } & 68.82 \\
& & 22.99
\end{tabular}

\section{Rendimiento por hectárea de café oro}

Los resultados del rendimiento por hectárea de café oro alcanzado en el ensayo, se muestran en la Tabla 7 . El rendimiento por hectárea de café oro más alto se obtuvo con la aplicación de Micro-Asp 6 l/ha + PF con 1,118.75 $\mathrm{kg} / \mathrm{ha}$, el cual fue estadísticamente superior al resto de tratamientos; sin embargo este fue estadísticamente igual al tratamiento Micro-Asp 9 l/ha + PF (668.82 Kg/ha). El registro más bajo de rendimiento se dio en el testigo absoluto sin aplicación de productos con $260.70 \mathrm{~kg} / \mathrm{ha}$.

Tabla 7. Rendimiento por hectárea de café oro.

\begin{tabular}{ccc}
\hline Tratamientos & Dosis/ha & Rendimiento (kg/ha) \\
Azospirillum artesanal & $1,200 \mathrm{~kg}$ & $311.42 \mathrm{~b}$ \\
Azospirillum artesanal & $2,400 \mathrm{~kg}$ & $579.55 \mathrm{~b}$ \\
Micro-Asp + P.F & $6,0 \mathrm{l}$ & $1,118.75 \mathrm{a}$ \\
Micro-Asp + P.F & $9,0 \mathrm{l}$ & $668.82 \mathrm{ab}$ \\
Micro-Azot + P.F & $6,0 \mathrm{l}$ & $480.38 \mathrm{~b}$ \\
Micro-Azot + P.F & $9,0 \mathrm{l}$ & $574.95 \mathrm{~b}$ \\
Micro-Asp & $6,0 \mathrm{l}$ & $583.52 \mathrm{~b}$ \\
Micro- Azot & $6,0 \mathrm{l}$ & $341.20 \mathrm{~b}$ \\
Testigo químico & $160 \mathrm{~kg}$ N-60 kg P-75 kg K & $541.38 \mathrm{~b}$ \\
Testigo absoluto & $0-0-0$ & $260.70 \mathrm{~b}$ \\
\multicolumn{2}{c}{ Coeficiente de variación \% } & 546.07 \\
& & 32.93 \\
\hline
\end{tabular}

\section{Análisis económico}

El análisis económico realizado a los tratamientos del ensayo, reporto que el tratamiento Micro-Asp $6 \mathrm{l} / \mathrm{ha}+\mathrm{PF}$ presentó la mejor utilidad con $\$ 1,814.04$, habiéndose encontrado la menor utilidad en Micro-Azot 6 1/ha + PF con \$17.26. 


\section{Discusión}

Las aplicaciones de biofertilizantes (Micro-Asp) y fertilizantes químicos sobre la variedad evaluada, influyeron de forma significativa en altura de planta y diámetro de tallo, esto es debido a que estas características agronómicas se ven influenciadas por la formación de hormonas reguladoras de crecimiento, en donde Bottini et al. (2004), manifiestan que muchas cepas de Azospirillum tienen la capacidad de producir otros reguladores de crecimiento (giberelinas, citocinas, ácido absísico y etileno) a una concentración suficiente para provocar cambios morfológicos y fisiológicos en las plantas. Esto también es corroborado por Jiménez (2008), quien menciona que en los últimos años el estudio de microorganismos asociados a plantas ha sido tema de interés para muchos investigadores, por todos los beneficios que estos pueden aportar a las plantas, entre estos: fijación biológica de nitrógeno, producción de hormonas, así como también la influencia de estos en el ecosistema. Así mismo con la inoculación de Azospirillum se observa frecuentemente un mayor desarrollo del sistema radical, el cual se traduce en mayor superficie de absorción de nutrientes, así como en mayor desarrollo de la parte aérea de las plantas. También se han observado incrementos en el contenido de nitrógeno, fósforo, potasio y otros minerales en las plantas inoculadas.

Por otra parte, las diferentes aplicaciones de Azospirillum mejoraron las caracteristicas agronómicas del cultivo de café, ya que estas facilitan la asimilación de los nuyrientes; el proceso de asimilación y nutrición es realizado de mejor manera, ya que la planta tiene los nutrientes en las etapas de máximo desarrollo, lo que no afecta la producción del cultivo. Esto se explica con lo manifestado por Rao y Krishna (2006), quienes mencionan que la asociación planta-bacterias fijadoras de nitrógeno ha sido estudiada en plantas anuales y perennes debido a que contribuyen en el efecto directo del crecimiento de la planta, por la producción de fitohormonas, en la disponibilidad de nutrimentos y en la reducción de las poblaciones de patógenos de la raíz.

El mayor rendimiento en grano oro, se encontró con la aplicación de Micro-Asp en dosis de 6 l/ha más programa de fertilización (PF). La aplicación de este producto estimula al cultivo, logrando que este alcance un crecimiento relativamente uniforme, lo cual es previsible ya que la aportación balanceada de nutrientes y su distribución en el sistema radicular estimulan el desarrollo vegetativo adecuado de las plantas, maximizando su potencial productivo. Esto concuerda con lo manifestado por Euroagro (2014), quienes manifiestan que la bacteria también promueve el crecimiento, el cual depende entre otras, de sustancias como el ácido acético del indol (IAA), las giberelinas, ayudando también a la formación de raíces principales y secundarias. 


\section{Conclusion}

Las aplicaciones de Azospirillum en mezclas o solos, tienen gran incidencia en las variables evaluadas, promoviendo el crecimiento y desarrollo de la planta, sin embargo la aplicación del programa de fertilización, no incidió significativamente sobre el rendimiento, pero supero matemáticamente al testigo.

Los rendimientos presentados fueron aceptables dadas las condiciones de la zona. Los rendimientos alcanzados para la variedad, lograron valores maximos con la aplicación de la fertilización y Azospirillum (1118.75 kg/ha café oro), las que superan considerablemente la producción media nacional y a los demás tratamientos. Los resultados obtenidos con la utilización de fertilizantes sin la aplicación de la bacteria, no superan a la mezcla de estos con fertilización convencional.

\section{References:}

1. Andrade, J. (2009). “Efecto de la inoculación con Azotobacter sp. en el crecimiento de plantas injertadas de cacao (Theobroma cacao L.), genotipo nacional, en la provincia de Esmeraldas”. Director: José Sergio Velázquez. Escuela Politécnica Nacional, Quito.

2. Arias, F; López, V; Guerrero, P. (2007). “Tratamiento de cultivos sin suelo”. Horticultura Ecológica. Ed mundipresa. vol 5, num. 2, p. 1315.

3. Bottini, R; Cassán, F; Piccoli, P. (2004). Gibberellin production by bacteria and its involvement in plant growth promotion and yield increase. Appl. Microbiol. Biotechnol. 65:497-503.

4. COFENAC. Situación actual del café. Catalogo (en línea). Disponible en Web: <http://www.cofenac.org/wp-content/uploads/2010/09/situacionsector-cafe-ecu 2013.pdf2/> (Consulta: 21 de mayo de 2014).

5. Clementi, F. (2006). Producción de Alginato por Azotobacter vinelandii. Crit Rev Biotechnol. Madrid, p. 327-61.

6. EUROAGRO. Manual y catálogo de productos (en línea). Disponible en Web: $<$ www.euroagro.com.ec $>$ (Consulta: 22 de mayo de 2014).

7. Jiménez, M. (2008). "Manejo de cultivos con biofertilización: fijadores biológicos de nitrógeno”. Importancia de microrganismos benéficos en los cultivos. vol 8, núm. 5, p. 20-65.

8. Kennedy, J.; Tchan, J. (1992). “Agricultura ecológica en Colombia y sus nuevas proyecciones”. In: Memorias II Congreso Nacional de Agricultura Ecológica. Bogotá, p. 230 -231.

9. Olalde, K; Portugal, P. (1998). "Reducción de biofertilizantes costos y daño ambiental”. Imagen agropecuaria. vol 1, num. 3, p.12-14. 
10. Rao, A; Khishna, F. (2006). "Influence of amino acids on Nitrogen Fixation ability and grown of Azospirillum spp". Applied Enviromental Microbiology. vol.54, núm. 1, p. 87-93.

11. Tapia, H. (1990). "Detección de bacterias benéficas en suelos con banano (Musa AAA, simmonds) cultivar 'gran enano' y su potencial para integrar un biofertilizante”. Importancia de las bacterias fijadoras de nitrógeno. vol 44, num. 6, p. 120-145. 